\title{
ТЕОРЕТИЧЕСКИЕ АСПЕКТЫ ГОСУДАРСТВЕННОГО СТРОИТЕЛЬСТВА
}

\section{THEORETICAL ASPECTS OF STATE-BUILDING}

K. Tsarev

Summary: Current article, based on a wide source base, deals with theoretical aspects of state-building. Many researchers consider the terms "state building" and "nation building" as interchangeable. Most important theoretical constructions, however, are centered around the state, but not the nation (the latter refers to the population itself, united by a historical past, common identity, culture, and language). The topic of the particular article is related to state institutions and their interaction with society.

Keywords: state-building, nation-building, military intervention, democratization, transition to democracy, transition of power.

\author{
Царёв Константин Константинович \\ Аспирант, Институт США и Канады РАН, Москва \\ konstantin.tsarev@mail.ru
}

Аннотация: В настоящей статье на основании широкой источниковой базы рассматриваются теоретические аспекты государственного строительства. Многие исследователи считают термины «государственное строительство» (state building) и «национальное строительство» (nation building) взаимозаменяемыми. Большинство теоретических построений, однако, сосредоточено вокруг государства, но не нации (под последней понимается само население, объединённое историческим прошлым, общей идентичностью, культурой и языком). Тематика данной статьи связана именно с государственными институтами и их взаимодействием с обществом.

Ключевые слова: государственное строительство, национальное строительство, вооружённая интервенция, демократизация, переход к демократии, транзит власти.

В сравнительной политологии теоретик модернизации Карл И. Фридрих подчёркивал, что «нация [40. с. 1 48; 90 - 109] - это любая сплочённая группа, обладающая независимостью в рамках международного сообщества, как это предусмотрено Организацией Объединённых Наций. Данная группа являет собой электорат, необходимый правительству для эффективного управления. Одобрение деятельности правительства, исходящее от данной группы, легитимизирует его как часть мирового порядка» [3. с. 31]. Государственное строительство представляло собой процесс (преимущественно внутреннего характера) ассимиляции и интеграции населения страны в формирующийся государственный аппарат, который мог быть отнюдь недемократичным в краткосрочной перспективе [25. с. 322, 326]. результата и его первичного агента.

Словарь английского языка Мэрриама-Вебстера даёт следующее определение демократии: а) «Демократия - правление народа; особенно - правление большинства»; б) «Демократия - правительство, в котором верховная власть делегируется народу и осуществляется им прямо или косвенно через представительную систему, обычно подразумевающую периодически проводимые свободные выборы». Merriam-Webster Online Dictionary. [Электронный ресурс]. URL: https://www.merriam-webster.com/dictionary/democracy (дата обращения: 25.08.2019). Философский словарь дополняет данную формулировку: «Демократия - форма государственно-политического устройства общества, при которой народ является источником власти. Признается право народа участвовать в решении государственных дел в сочетании с широким кругом гражданских прав и свобод». Философский энциклопедический словарь. 1983. [Электронный реcypc]. URL: http://www.runivers.ru/philosophy/lib/book6207/140184/ (дата обращения: 25.08.2017). Практически все американские авторы, пишущие сегодня о демократии, исходят из презумпции, что она хороша в любом виде - мысль, которую лучше других выразил Ларри Даймонд. «...Демократия - это в общем благо и наилучшая форма правления... Даже если воспринимать демократию просто как народовластие, как систему избрания руководителей посредством регулярно проводимых свободных и честных выборов, избранная таким способом власть в принципе лучше, чем сформированная каким-либо другим образом». Лучше потому, поясняет Даймонд, что «она создает наилучшие условия для ответственного, отзывчивого, миролюбивого, предсказуемого и справедливого управления». См. Даймонд Л. Определение и развитие демократии // Теория и практика демократии. Избранные тексты. С. 25. И, как обоснованно отмечает Роберт Даль, «в отличие от любой возможной альтернативы она [демократия] поддерживает свободу». Cм. Dahl R.A. Democracy and Its Critics. New Haven (Ct.), L., 1989, Ch. 8. P. $88-89$. 
Для Карла Дойча процесс государственного строительства был преднамеренным и осознанным: «Дом может быть построен из дерева, кирпича и известкового раствора; по разным лекалам; быстро или медленно; с разной последовательностью действий; отчасти независимо от местности, [где он будет возведён]; в зависимости от выбора, воли и силы строителей. Поэтому государство можно построить по разным чертежам, из разных материалов, быстро или поступательно, с разной последовательностью действий и отчасти независимо от окружающей среды» [21. с. 27]. Концепция Дойча остаётся актуальной и сегодня.

Примечательно, что в настоящее время государственное строительство предполагает формирование демократического государства, о чём свидетельствует его определение, данное Карин фон Хиппель: «В последние годы государственное строительство означало попытку создания необязательно демократичного, но [предпочтительно] стабильного правительства. Сегодня государственное строительство обычно подразумевает попытку создания демократических и безопасных государств²»[37. с. 96]. Связав демократизацию и создание функционального национального государства, фон Хиппель лишь усложнила понимание государственного строительства ${ }^{3}$.

Тем не менее, многие исследователи разделяют взгляд фон Хиппель на государственное строительство, как построение демократии, осуществляемое извне. Более общее определение звучит следующим образом: «Государственное строительство - это вмешательство в дела государства для предотвращения гражданских конфликтов и продвижения [необходимой] формы правления» [6. с. 2].

За последние сто лет западные демократические государства неоднократно пытались распространять демократию «на штыках», однако, учёные по-прежнему расходятся во мнениях касательно возможности навязывания устойчивых демократических институтов путём вооружённой интервенции 4 .

Апологеты данной точки зрения указывают на успешный опыт трансформации Западной Германии и Японии в устойчивые демократии после Второй мировой войны, считая его [опыт] доказательством возможности построения демократии третьими лицами через военное вмешательство [4; 13; 5; 19; 10; 18. с. 112 - 156; 30. с. 67 - 94].

Противники данного подхода считают эти прецеденты исключением из общей полосы неудач, которыми закончилось вмешательство в дела Ирака, Афганистана и действия США в Центральной Америке и Карибском бассейне в начале XX в. Авторы некоторых недавних исследований пришли к выводу, что интервенция не оказывает никакого влияния или даже негативно влияет на последующее движение страны к демократии [2. с. 627 - 649; 17. с. 539 - 560; 35. с. 147 - 162; 31; 1. с. 120 - 147; 38; 24. c. $59-92]$.

Кондиционалисты, в целом, согласны, что «демократическая» вооружённая интервенция мало влияет на либерализацию целевых государств, но утверждают, что демократические государства могут стимулировать процесс демократизации при: а) реальной заинтересованности в достижении данной цели; б) инвестировании значительных сил и ресурсов [28; 27. с. 549 - 582; 26. с. 91 - 114; 16. с. 391 - 402; 15].

Джеймс Доббинс и его соавторы выдвинули наиболее распространённый тезис о том, что «множество факторов влияет на простоту или сложность государственного строительства. Однако, среди контролируемых факторов, наиболее важным детерминантом является степень вовлечённости, измеряемая временем, живой силой и объёмом инвестиций» [14. с. 25]. Установив связь между степенью вовлечённости и конечным результатом, эксперты отмечают, что «не существует быстрого способа построить государство. Пять лет - это минимум для обеспечения устойчивого перехода к демократии» [14. с. 166].

Акцент на вмешательстве и администрировании извне превращает государственное строительство в международный процесс и символизирует дальнейшую трансформацию изначальной концепции. Дойч и его современники предполагали, что местные лидеры станут катализатором перемен, и сомневались в эффективности воздействия внешних сил: «Фактическая способ-

2 Secure state - безопасное государство или, буквально, «безопасное состояние».

3 Действительно, определение, данное фон Хиппель, противоречит мнению некоторых компаративистов о том, что национальность и государственность хронологически и причинно предшествуют демократизации. О дискуссиях по этому вопросу см.: Dankwart Rustow, "Transitions to Democracy: Toward a Dynamic Model", Comparative Politics 2 (April 1970), pp. 350-52; Juan J. Linz and Alfred Stepan, Problems of Democratic Transition and Consolidation: Southern Europe, South America, and Post-Communist Europe (Baltimore: Johns Hopkins University Press, 1996), pp. 24-29.

4 Незадолго до и с момента окончания Холодной войны, Соединённые Штаты и их демократические союзники совершили вооружённую интервенцию (по крайней мере частично для установления демократического правления) в Панаму (1989), Гаити (1994), Боснию (1995), Югославию/Косово (1999), Афганистан (2001), Ирак (2003), и Ливию (2011). 
ность многих молодых государств к самоуправлению и поддержанию политической стабильности была весьма ограниченной. Политическая нестабильность в Конго, Лаосе, Вьетнаме и других молодых государствах была чрезвычайно велика. Поддерживать власть иностранцев в подобных странах было бы ещё сложнее и дороже» [22. c. 8].

Джеймс Доббинс определяет государственное строительство, как «использование вооружённой силы в постконфликтный период для поддержания планомерного перехода к демократии» [10. с. 218]. Учитывая большое количество несостоявшихся государств, Фрэнсис Фукуяма задавался вопросом, «существует ли реальная альтернатива квазистационарным ${ }^{5}$, квазиколониальным отношениям между страной-«бенефициаром» и международным сообществом» [11. с. 104]. Стивен Краснер согласился, что «Повышение эффективности внутренней политики в плохо управляемых, несостоявшихся и оккупированных государствах потребует преодоления 6 сложившихся норм, в том числе создания зон совместного суверенитета7 в конкретных областях» [23. с. 85]. Ниал Фергюсон пришёл к выводу, что автократии и несостоявшиеся государства не смогут реформировать себя самостоятельно и будут нуждаться в реформировании внешними силами [9. с. 24].

Этот теоретический сдвиг сопровождался увеличением числа интервенций в 90-е гг. и получил оформление в ходе дискуссий о создании «здоровых» [стабильных] правительств в зарубежных странах после террористических атак 11 сентября 2001 г.

Императивы национальной безопасности побудили США рассмотреть возможность создания государственных институтов там, где они не были сформированы в ходе политического развития. После атак на Всемирный торговый центр и Пентагон Дж. Буш-мл. заявил, что не только уничтожит коррумпированные государства ${ }^{8}$, но перестроит их: «Сегодня угроза для Америки исходит не от завоевательных ${ }^{9}$, но от несостоявшихся ${ }^{10}$ государств. Нам угрожают ни армии или корабли, но разрушительные технологии в руках озлобленного меньшинства»
[36. с. 1]. К осени 2005 г. демократизация была объявлена главным инструментом повышения национальной безопасности, при этом одной из целей разведслужб было «нанести поражение терроризму внутри страны и за её пределами, уничтожить его боевые средства и перехватить инициативу, способствуя распространению идей свободы и демократии» [32. с. 4].

После определения деспотизма и терроризма в качестве основных угроз, учёные сошлись во мнении, что иностранная интервенция является решением на долгосрочную перспективу. С одной стороны, навязываемая извне демократизация давно вышла за границы привычного укрепления демократии, которое не предполагало вооружённой оккупации. С другой стороны, после Второй мировой войны шло закономерное развитие политической науки. Компаративисты ${ }^{11}$ от Роберта Алана Даля до Роберта Л. Джексона утверждали, что иностранные державы не оказывают большого влияния на внутреннее развитие других стран, если последние не находятся под управлением коренного народа, стимулирующего развитие необходимых институтов. Даль считал американскую оккупацию Японии и Германии исключением, только подтверждавшим необходимость опоры на местные элиты [33. с. 200]. Джексон считал колониальную политику Великобритании в Африке образцом для проведения политических реформ [34. с. 202].

После террористических актов 11 сентября учёные отреагировали на изменения в международной обстановке и сосредоточились на проблеме стратегии национальной безопасности. Власть Соединённых Штатов начала рассматриваться, как средство правовой защиты от нефункциональных политических режимов. После террористических актов 11 сентября Джордж У. Буш провозгласил решительную демократизацию способом борьбы с террористической угрозой, которая исходила от авторитарных государств Ближнего Востока [12]. Администрация Буша оправдывала вторжение в Ирак и свержение режима Саддама Хуссейна дальнейшей демократизацией Ирака, которая должна была стимулировать волну либерализации стран Ближнего Востока и устранение репрессивных режимов, спонсировавших международный терроризм.

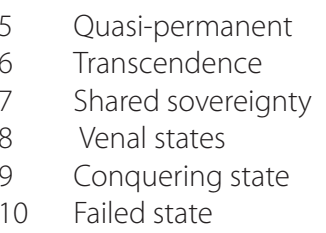

11 Сравнительная политология - одно из направлений политической науки. Основным методом сравнительной политологии выступает метод сравнения. Отсюда происходит ещё одно название этого направления - компаративистика. Сравнительная политология занимается изучением политики путём сравнения и сопоставления однотипных политических явлений в различных политических системax. 


\section{ЛИТЕРАТУРА}

1. Arthur A. Goldsmith. Making the World Safe for Partial Democracy? Questioning the Premises of Democracy Promotion // International Security. - Vol. 33. - No. 2 (Fall 2008). - PP. 120 - 147.

2. Bruce Bueno de Mesquita and George W. Downs Intervention and Democracy // International Organization. - Vol. 60. - No. 3 (Summer 2006). - PP. 627 - 649.

3. Carl J. Friedrich. Nation-Building? in Karl W. Deutsch and William J. Foltz, eds. // Nation-Building (New York: Atherton, 1963). - P. 31.

4. Charles Krauthammer. Democratic Realism: An American Foreign Policy for a Unipolar World. - 2004.

5. Condoleezza Rice. The Promise of Democratic Peace: Why Promoting Freedom Is the Only Realistic Path to Security // Washington Post. - December 11. - 2005.

6. Cynthia A. Watson, Nation-Building: A Reference Handbook. -Santa Barbara: ABC-CLI0, 2004. - P. 2.

7. Dahl R.A. Democracy and Its Critics. New Haven (Ct.), L., 1989. - Ch. 8. -PP. 88 - 89.

8. Dankwart Rustow. Transitions to Democracy: Toward a Dynamic Model // Comparative Politics 2 (April 1970). - PP. 350 - 352.

9. Ferguson. Colossus: The Price of Americas Empire //New York: Penguin Press, 2004. - P. 24.

10. Francis Fukuyama. America at the Crossroads: Democracy, Power, and the Neoconservative Legacy. - New Haven, Conn.: Yale University Press. - 2006.

11. Fukuyama, State-Building. Governance and World Order in the 21st Century. - Ithaca, N.Y.: Cornell University Press, 2004. - P. 104.

12. George W. Bush. The National Security Strategy of the United States of America. - Washington, D.C.: White House, 2002.

13. Irving Kristol Lecture. American Enterprise Institute. - Washington, D.C., February 10, 2004

14. James Dobbins et at. America's role in nation-building: from Germany to Iraq. - RAND, 2003 - - P. 25.

15. James Dobbins, John G. McGinn, Keith Crane, Seth G. Jones, Rollie Lal, Andrew Rathmell, Rachel Swanger, and Anga Timilsina, America's Role in Nation-Building: From Germany to Iraq (Washington, D.C.: RAND, 2003).

16. James Meernik. United States Military Intervention and the Promotion of Democracy // Journal of Peace Research. - Vol. 33. - No. 4 (November 1996). - PP. 391 402.

17. Jeffrey Pickering and Mark Peceny. Forging Democracy at Gunpoint // International Studies Quarterly. - Vol. 50. - No. 3 (September 2006). - PP. 539 - 560.

18. Jonathan Monten. The Roots of the Bush Doctrine: Power, Nationalism, and Democracy Promotion in U.S. Strategy // International Security. Vol. 29. - No. 4 (Spring 2005). - PP. $112-156$.

19. Joshua Muravchik. Exporting Democracy: Fulfilling America's Destiny. - Washington, D.C.: American Enterprise Institute, 1992. - chap. 8.

20. Juan J. Linz and Alfred Stepan, Problems of Democratic Transition and Consolidation: Southern Europe, South America, and Post-Communist Europe. - Baltimore: Johns Hopkins University Press, 1996. - PP. $24-29$.

21. Karl W. Deutsch. Some Problems in Nation-Building,» in Deutsch and Foltz. - P. 3.

22. Karl W. Deutsch. The Study of Nation-Building, 1962-1966 in Deutsch and Foltz (fn. 3). - P. 8.

23. Krasner. Sharing Sovereignty: New Institutions for Collapsed and Failing States // International Security 29 (Fall 2004). - P. 85.

24. Laurence Whitehead. The Imposition of Democracy: The Caribbean in Whitehead, ed., The International Dimensions of Democratization: Europe and the Americas. - Oxford: Oxford University Press, 1996. - PP. 59 - 92.

25. Manfred Halpern. Toward Further Modernization of the Study of New Nations. World Politics 17 (October 1964); Walker Connor, «Nation-Building or NationDestroying?» World Politics 24 (April 1972). - PP. 322, 326.

26. Margaret G. Hermann and Charles W. Kegley Jr. The U.S. Use of Military Intervention to Promote Democracy: Evaluating the Record» // International Interactions. Vol. 24. - No. 2 (June 1998). - PP. 91 - 114.

27. Mark Peceny. Forcing Them to Be Free // Political Research Quarterly. - Vol. 52. - No. 3 (September 1999). - PP. 549 - 582.

28. Mark Peceny. Democracy at the Point of Bayonets. - University Park: Pennsylvania State University Press, 1999.

29. Merriam-Webster Online Dictionary. [Электронный ресурс]. URL: https://www.merriam-webster.com/dictionary/democracy (дата 06ращения: 25.04.2021)

30. Nancy Bermeo. Armed Conflict and the Durability of Electoral Democracy in Ronald Krebs and Elizabeth Kier, eds., In War's Wake: International Conflict and the Fate of Liberal Democracy. - Cambridge: Cambridge University Press, 2010. - PP. 67 - 94.

31. Nils Gleditsch, Lene Siljeholm Christiansen, and Håvard Hegre. Democratic Jihad? Military Intervention and Democracy // World Bank Policy Research Working Paper, No. 4242; Washington, D.C.: World Bank. - June 2007.

32. Office of the Director of National Intelligence, National Intelligence Strategy of the United States of America. - Washington, D.C.: Office of the Director of National Intelligence, 2005. - P. 4.

33. Robert A. Dahl. Polyarchy: Participation and Opposition. New Haven: Yale University Press 1971. - P. 200.

34. Robert H. Jackson. Quasi-States: Sovereignty, International Relations, and the Third World. - New York: Cambridge University Press, 1990. - P. 202.

35. Scott Gates and Håvard Strand. Military Intervention, Democratization, and Post-Conflict Political Stability in Magnus Öberg and Kaare Strøm, eds., Resources, Governance, and Civil Conflict. - London: Routledge, 2008. - PP. 147 - 162.

36. The White House, National Security Strategy of the United States. - Washington, D.C.: The White House, 2002. - P. 1.

37. Von Hippel. Democracy by Force: A Renewed Commitment to Nation-Building. - Washington Quarterly 23 (Winter 2000). - P. 96.

38. William Easterly, Shanker Satyanath, and Daniel Berger. Superpower Interventions and Their Consequences for Democracy: An Empirical Inquiry. - Working Paper, No. 13992 (Cambridge, Mass.: National Bureau of Economic Research, May 2008. 
39. Даймонд Л. Определение и развитие демократии // Теория и практика демократии. Избранные тексты. - С. 25.

40. Нация и национализм. История и теория в текстах и документах. / Авт.-сост., общ. ред. и предисловие 0.И. Аршба и С.А. Татунц. - М.: Рик Русанова, 2002. CC. $1-48 ; 90-109$.

41. Философский энциклопедический словарь. 1983. [Электронный ресурc]. URL: http://www.runivers.ru/philosophy/lib/book6207/140184/ (дата обращения: 25.04.2021).

() Царёв Константин Константинович (konstantin.tsarev@mail.ru).

Журнал «Современная наука: актуальные проблемы теории и практики»

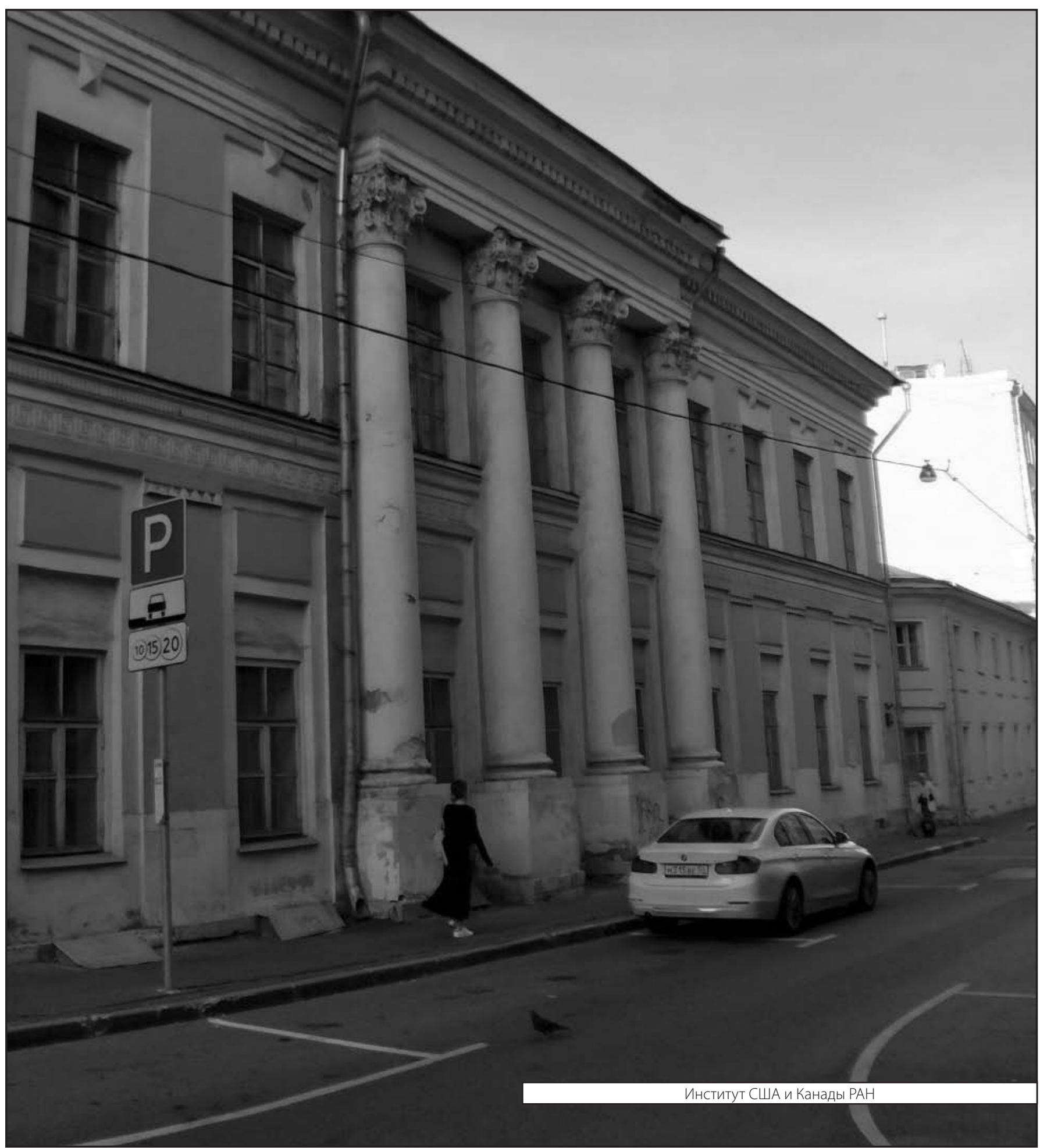

